\title{
Saúde e ambiente nos seringais do Acre boliviano (1870-1903): o papel de fatores e processos exógenos
}

\author{
Health and environment in the rubber-tree plantations \\ in the Bolivian Acre (1870-1903): the role of exogenous factors \\ and processes
}

Domingos José de Almeida Neto ${ }^{1}$

Léo Heller ${ }^{2}$

${ }^{1}$ Reitoria, Universidade Federal do Acre. BR-364/ Km 04, Distrito Industrial. 69.920-900 Rio Branco AC Brasil. dojoalne2008@ hotmail.com

${ }^{2}$ Departamento de

Engenharia Sanitária e Ambiental, Universidade Federal de Minas Gerais.
Abstract A peculiar situation marks the conditions of human and environmental health in the first major cycle of rubber production in the Acre region of the Western Amazon, whereby the bulk of the boom (1870-1903) occurred in the territory that at that time still belonged to Bolivia. Based on this historical background, this work seeks to describe and comprehend how these factors and processes, which are exogenous to these two fields of analysis mediated the risks that originated in the environment, gave rise to sickness and death in the population of the "Brazilian" rubber-tree plantations established in Bolivian territory. In this manner, the inter-relations between health and environment linked to historically specific configurations of the physical-natural, socioeconomic, political, and cultural conditions, are examined. The work shows that these extrinsic factors and processes to the productive activities exerted an influence not only on its organizational but also functional aspects, while also resulting in the unhealthy conditions observed in the productive regions. It further highlights the fact that the extant infrastructure of the time was sufficient for extractive production and reproduction.

Key words Environmental health, Sanitation, Rubber-latex, Sickness, Risk
Resumo Situação particular marca as condições da saúde humana e do ambiente no primeiro surto da produção gomífera na Amazônia Ocidental, região do Acre, sendo que a maior parte dele (1870-1903) ocorreu em território ainda pertencente à Bolivia. Com base nesse quadro histórico, o trabalho busca descrever e compreender como fatores e processos exógenos a esses dois campos de análise mediavam os riscos, com origem no ambiente, para o adoecimento e a morte nas populações dos seringais "brasileiros" em território boliviano. Explora-se, assim, a inter-relação entre saúde e ambiente, a partir das configurações historicamente específicas das condições físico-naturais, socioeconômicas, politicas e culturais. $O$ trabalho evidencia que esses fatores e processos extrínsecos às atividades produtivas exerceram não só influência, tanto em seu aspecto organizativo quanto funcional, como determinaram as condições insalubres que se observaram nas regiões produtoras. Aponta, ainda, que a infraestrutura então existente era suficiente para a produção e a reprodução extrativista.

Palavras-chave Saúde ambiental, Saneamento, Borracha, Doença, Risco 


\section{Introdução}

Observar as relações entre o ambiente e a saúde humana, bem como as condições de saneamento, interligando-as, em determinado contexto histórico, permite ao estudioso seguir algumas trilhas para chegar à compreensão desse processo simbiótico $^{1-3}$. Aqui, neste estudo, optou-se por uma percepção dessa inter-relação nos seringais 'brasileiros' do então Acre boliviano (1870-1903), a partir da ausência de intervenção pública e, ainda, sob a seguinte premissa transladada para o passado: "[...] as políticas públicas e a gestão no campo do saneamento dependem das configurações historicamente específicas das condições físico-naturais, socioeconômicas, políticas e culturais que caracterizam os diferentes países e regiões." ${ }^{\text {. }}$

Olhando-se sob esse ângulo das 'configurações históricas', percebe-se que a falta da intervenção pública, no tocante à gestão no campo do saneamento, no local geográfico e no momento histórico, está intimamente relacionada às condições socioeconômicas e mesmo tecnológicas em que vivia o país.

Mas o estudo não se atém somente aos fatores ambientais, socioeconômicos e políticos culturais da época. Vai além, lança mão das categorias analíticas, tais como higiene e salubridade, como fatores essenciais para a compreensão das relações entre ambiente e saúde, homem e natureza, muito embora se saiba que, nesse marcado período, as mudanças epistemológicas sobre a explicação do processo saúde-doença se encontravam em curso, bem como transformações nas concepções ontológicas de doenças fizessem parte das matrizes explicativas da época.

Levando-se em conta a ausência do poder público e o contexto histórico em questão, entenda-se por higiene aquelas ações de caráter predominantemente individual (por exemplo, alimentação, vestuário e asseio corporal); e por salubridade as questões relacionadas ao ambiente físico (tais como a limpeza dos terrenos, o acesso à água e a presença de animais peçonhentos). Assim, parte-se da premissa de que tais condições comportamentais e ambientais poderiam expor os produtores de borracha - como expresso na atualidade pela legislação que regulamenta as condições de trabalho no Brasil - “[...] a agentes nocivos à saúde, acima dos limites de tolerância fixados em razão da natureza e da intensidade do agente e do tempo de exposição aos seus efeitos."5.

Para este estudo, as informações originaramse de fontes documentais de caráter primário e secundário, acadêmicas e/ou oficiais, por serem aquelas que permitiram elucidar os fatos e situações históricas de interesse para o propósito deste artigo. Não se buscou realizar entrevistas ou outras formas para resgatar a memória dos envolvidos na análise - principalmente ex-seringueiros, residentes nos bairros periféricos de Rio Branco, muito embora se tenha consciência de que são esses sujeitos que fundamentam a história de vida regional, nos seus mais diversos aspectos. E tanto assim é que, se eles não foram ouvidos diretamente, o foram por intermédio de suas vozes grafadas em diversos documentos, produtos de outras pesquisas realizadas durante algumas fases representativas da produção de borracha no Acre.

Então, essa opção de se recuperarem as reminiscências dos ex-seringueiros, por meio de fontes secundárias, justifica-se pelo fato de já se ter passado mais de 100 anos do colapso do primeiro surto da produção da goma elástica. Assim, é improvável que se possa encontrar algum remanescente desse período, mesmo que ele estivesse, à época, no limiar de sua infância.

De igual modo, ainda que se buscassem informações junto aos extratores que vivenciaram o segundo surto gomífero, como estratégia para se fazer uma analogia com o primeiro, elas não seriam satisfatórias, considerando, dentre outros aspectos, a idade avançada desses sobreviventes que não lhes permitiria lembrar desse tempo longínquo para eles. Prova disso é que, em conversa informal recente com um 'ex-soldado da borracha', com mais de 80 anos de idade, pode-se notar o quão poderia ser constrangedor abordar esses agentes da história acriana, dada a dificuldade do interlocutor em fazê-los relembrar aquele período e nele recordar aspectos relativos à higiene pessoal, como por exemplo, o ambiente utilizado para a defecação tão diverso deste do século XXI.

Ainda, com relação aos depoimentos orais tomados por outros pesquisadores, projetam-se, na medida do possível, as falas dos entrevistados para o passado, mais precisamente para o período relativo ao primeiro surto, uma vez que não se têm notícias de coleta de informações junto aos sujeitos históricos diretamente relacionados com esse referido tempo. Tal opção metodológica leva em conta que um número considerável desses entrevistados, na condição de descendentes diretos dos primeiros extratores do látex, faz questão de mencionar não só essa descendência, como também traduzir, pelos relatos, as condições da produção naquele momento que 'ouviram contar' dos antepassados.

Há que se esclarecer, por oportuno, que ao se tratar das inter-relações associadas à produção 
gomífera, a partir da perspectiva dos fatores e processos que lhes foram subjacentes, devem ser apresentadas algumas ressalvas:

a) o meio geográfico no qual se deu o processo produtivo da borracha, em um ambiente de floresta densa e praticamente despovoada, que não possuía as características comuns de um aglomerado populacional capaz de ensejar intervenções clássicas em saneamento, uma vez que estava distante de se caracterizar como lugar urbano e, sequer, não se enquadrava no conceito tradicional de meio rural;

b) a tarefa de fabricação de borracha, considerando o seu caráter produtivo, o que menos importou - para aqueles com ela envolvidos, pelo menos durante o primeiro surto e, particularmente, para o período em que o Acre se encontrava sob o auspício boliviano - foram as condições de higiene e salubridade. Isso porque, se por um lado não havia a intenção de fixação dos produtores nos seringais, por outro o próprio sistema, calcado na ganância por enriquecimento precoce, não permitia outras atividades para além do fabrico da borracha.

c) a impossibilidade de se falar em intervenção, porquanto, como até antes da assinatura do tratado de Petrópolis, em 1903, o Acre pertencia à Bolívia. Então não estava sob a jurisdição do poder público brasileiro, a não ser pela parca $\mathrm{e}$ oficiosa ação administrativa que o Estado do Amazonas ali exercia, beneficiando-se da arrecadação de impostos sobre a produção de borracha.

d) a Bolívia, a exemplo do Brasil, só se interessou pela demarcação das terras do Acre - cuja principal informação a esse respeito é o relatório do próprio ministro plenipotenciário daquele país no Brasil, José Paravicini ${ }^{6}$ - quando este passou a representar uma força na produção de borracha. Todavia, nenhum dos lados ocupava-se com a situação da higiene e da salubridade nos seringais.

Também, deve ser destacada a existência de uma historiografia acriana, descrita sob múltiplas abordagens, e relacionada não só aos dois 'surtos' da produção de borracha (1870-1912 e 1942-1947), mas também às três décadas de franca estagnação produtiva, cujo processo envolveu todo o Vale Amazônico. Tais abordagens abraçam as mais diversas áreas do conhecimento, tais como a sociologia, a história, a economia, a geografia e a saúde. Assim, ao se tomar a iniciativa de (re)escrever sobre os modos de vida das gentes do Acre, sob a ótica de quaisquer das disciplinas científicas, tem-se a sensação de que todos os caminhos já foram percorridos e que os possíveis acontecimentos, com eles relacionados, foram devidamente narrados e interpretados. Entretanto, não se localizam, na literatura, abordagens que busquem relacionar as situações associadas ao ambiente e à saúde humana daquele período e daquela região, bem como sua articulação com as condições de higiene e de insalubridade dos seringais e da influência de fatores e processos exógenos.

\section{As condições gerais de vida e de (re)produção do seringueiro}

No caso do Acre, pode-se identificar uma inter-relação entre a sociedade e o ambiente físico, ou mais especificamente do ser humano com o rio e com a floresta nativa, em vários períodos históricos. Foram períodos caracterizados por formas distintas de ocupação do território, sendo que, aqui, aborda-se, especialmente, o período denominado de primeiro surto produtivo da borracha e, nele, em mais detalhes o período em que a região acriana se encontrava sob domínio boliviano.

Nessa ocasião o Acre constituía-se de uma vastidão de floresta nativa, de modo que, se não fosse por via fluvial, não havia como adentrar o coração da selva e explorar as árvores produtoras da goma elástica. E, num processo inverso, também pelos rios se escoava a borracha até os portos de Manaus e de Belém.

Mais tarde, com o advento do látex como matéria-prima essencial para as indústrias europeias e norte-americanas, a Amazônia - e o Acre em particular - vivenciou, por volta de 1870, o início de uma nova e importante fase de ocupação, mas que, "para conseguir braços, foi necessário incentivar a migração, já que os nativos [não índios nascidos aqui] e índios se mostraram insuficientes"'.

Então, o traslado de pessoas do Nordeste para esse setor da Amazônia começou - preconizado pelos governos nordestinos e pelo Império - no intuito de solucionar a crise econômica daquela região que passava intenso período de seca. Assim, resolveria o governo do Brasil os problemas sociais da Amazônia e do Nordeste, bem como atenderia a iniciativa privada brasileira ${ }^{8}$.

Não obstante a demora no deslocamento entre o local de origem até o destino final, as condições de higiene não eram nada satisfatórias ou alentadoras. Isto se verificava desde os acampamentos superlotados no Nordeste, ocupados antes do embarque. Depois, durante o trajeto, pois o migrante viajava na terceira classe, sofrendo ali 
outras agruras, como excesso de contingente, má alimentação e o calor elevado nos porões dos navios. Era um grande sofrimento até o desembarque nas hospedarias de Belém e Manaus ${ }^{9,10}$.

Fato importante a ser considerado, nesse aspecto, é que o migrante nordestino, o chamado 'arigó', ao ser arregimentado, já contraía as primeiras dívidas com o seu patrão seringalista:

O seringueiro é um homem que trabalha para escravizar-se [...]. No próprio dia em que parte do Ceará, o seringueiro principia a dever: deve a passagem de proa até o Pará (35\$000), e o dinheiro que recebeu para preparar-se (150\$000). Depois vem a importância do transporte, num 'gaiola' qualquer de Belém ao barracão longínquo a que se destina, e que é na média de $150 \$ 000^{11}$.

Mas as primeiras dívidas não paravam por aí, uma vez que, ao chegar ao seu local de destino, tinha que se prover de utensílios de uso doméstico e também daqueles destinados ao próprio trabalho, além de 'mantimentos' ou víveres:

Aditem-se cerca de $800 \$ 000$ para os seguintes utensílios invariáveis: um boião de furo, uma bacia, mil tigelinhas, uma machadinha de ferro, um machado, um terçado, um 'rifle' (carabina Winnchester) e duzentas balas, dous pratos, duas colheres duas chicaras, duas panelas, uma cafeteira, dois carretéis de linha e um agulheiro. Nada mais. Aí temos o nosso homem no 'barracão' senhorial, antes de seguir para a barraca, no centro, que o patrão designará. Ainda é um 'brabo', isto é, ainda não aprendeu o 'corte da madeira' e já deve 1:135\$000. Segue para o posto solitário encalçado de um comboio levando-lhe a bagagem e víveres, rigorosamente marcados, que lhe bastem para três meses: 3 'paneiros' de farinha de água, 1 saco de feijão, outro, pequeno, de sal, 20 quilos de arroz, 30 de charque, 21 de café, 30 de açúcar, 6 latas de banha, 8 libras de fumo, e 20 gramas de quinino. Tudo the custa cerca de 750\$000. Ainda não deu um talho, de machadinha, ainda é o 'brabo' canhestro, de quem chasqueiam o 'manso' experimentado, e já tem o compromisso sério de 2:090\$000 ${ }^{11}$.

Essas citações explicitam, por si mesmas, vários aspectos do viver nos seringais e relação dos 'senhores' com as condições materiais e humanas dos produtores da borracha, permitindo, inclusive - numa leitura mais acurada - entrever uma relação entre a alimentação e o processo saúdedoença do seringueiro.

\section{Alimentação, ambiente, modo de produção e a relação saúde-doença}

Veja-se que a alimentação se limitava ao consumo de farinha, feijão, sal, arroz, charque, café, açúcar e banha. Uma análise quantitativa rápida desses víveres, definidos para três meses (ainda que se leve em conta os possíveis exageros da informação oferecida por Cunha), apontará que o consumo diário era bastante inferior à ingestão mínima necessária para o sustento, conforme verificado na Tabela 1 . Baseando-se na quantidade de gêneros alimentícios, para atender os seringueiros por três meses, e adotando-se uma massa de $30 \mathrm{~kg}$ para o paneiro de farinha - totalizando $90 \mathrm{~kg}$ - para o feijão igual ao do arroz e, para a banha, a lata de $2 \mathrm{~kg}$, dividiu-se a referida quantidade por 90 dias, obtendo-se o percentual médio diário de gêneros alimentícios. A partir dessas quantidades, foram estimadas as calorias correspondentes a cada macronutriente (carboidrato, proteína e lipídeos), totalizando a quantidade de calorias diárias ingeridas, em $1.840 \mathrm{kcal}$, muito

Tabela 1. Análise nutricional dos alimentos que faziam parte da refeição diária dos seringueiros, na condição de produtores exclusivos da borracha.

\begin{tabular}{lcccc}
\hline \multicolumn{1}{c}{ Alimentos } & $\begin{array}{c}\text { Carboidrato } \\
(\mathbf{k c a l} / \mathbf{d i a})\end{array}$ & $\begin{array}{c}\text { Proteína } \\
(\mathbf{k c a l} / \mathbf{d i a})\end{array}$ & $\begin{array}{c}\text { Proteína } \\
(\mathbf{g} / \mathbf{d i a})\end{array}$ & $\begin{array}{c}\text { Lipídeo } \\
(\mathbf{k c a l} / \mathbf{d i a})\end{array}$ \\
\hline Arroz cru & 141,5 & 12,88 & 3,22 & 6,55 \\
Feijão cru & 36,88 & 14,84 & 3,71 & 7,11 \\
Charque & 0 & 140 & 35 & 96,66 \\
Café & 25,9 & 7,7 & 1,92 & 0,233 \\
Açúcar & 333 & 0 & 0 & 0 \\
Banha & 0 & 0 & 0 & 133,24 \\
Farinha de mandioca & 864 & 17 & 4,25 & 3 \\
& $1.401,28$ kcal & $192,42 \mathrm{Kcal}$ & $48,1 \mathrm{~g} /$ dia & $246,793 \mathrm{kcal}$ \\
Proporção $(\%)$ & Valor Energético Total & $1.840,49 \mathrm{kcal} / \mathrm{dia}$ & - \\
\hline
\end{tabular}

Fonte: Para realização do cálculo das calorias, tomou-se como referência o trabalho de Phillipi ${ }^{12}$. 
inferior à média de $2500 \mathrm{kcal} /$ dia recomendada para o sexo masculino. Dessa forma, apura-se um déficit diário de $660 \mathrm{kcal}$, deixando assim o trabalhador da seringa mais exposto às doenças em razão da desnutrição e das condições de trabalho, saneamento e habitação.

Ainda com relação à alimentação do seringueiro, convém destacar que os embutidos (conservas e congêneres) eram amplamente usados ${ }^{13}$, e, a exemplo da base alimentar acima citada, além de não lhe proverem o sustento necessário, foram, ao que tudo indica, responsáveis pelo seu desequilíbrio orgânico, lento e gradual, a ponto de provocar doenças como o beribéri, pois, conforme se pode constatar:

O beribéri é um fator de insalubridade da Amazônia, constante, embora com exacerbações, até de caráter epidêmico. Ele deriva de uma insuficiência alimentar, por alimentos pobres de vitaminas, talvez alguns deteriorados, privados outros de substância frescas ${ }^{14}$.

Faz-se necessário evidenciar que não existia consenso científico sobre a relação entre alimentação e beribéri, na época em questão. Entretanto, partilhando dessa ideia sobre a associação dessa doença e o hábito alimentar determinado pelo modo de produção naquele espaço geográfico, Castro ${ }^{15}$ observa que:

E quando o ciclo da borracha se encerrou, o produto vindo a representar menos de $1 \%$ do volume da exportação brasileira, o beribéri desapareceu da região da borracha. É que, sem o excesso de dinheiro para queimar à toa, para comprar bebidas finas $e$ corned-beef inglês, o homem da Amazônia teve que voltar a seus antigos misteres da era de antes da borracha. À sua caça, à sua pesca, à sua colheita de raizes e frutos silvestres, à sua agricultura incipiente. Agricultura rudimentar, mas capaz de fornecer alguns produtos frescos: milho, feijão verde, favas e legumes que, com os produtos da colheita nativa, melhoram muito seu padrão de dieta, anulando a carência e exterminando, deste modo, o beribéri.

Embora o meio físico-natural da região permitisse uma alimentação adequada, baseada em frutas frescas, verduras, grãos, aves, carne vermelha, ovos e peixes, uma vez que fosse permitida a criação de animais, a caça, a pesca e a prática de uma agricultura de subsistência, esta foi cerceada pelas próprias condições inerentes ao processo produtivo, não permitindo, de fato, que a situação alimentar dos seringueiros fosse diferente daquela que se conhece pela história oral e pela literatura.

E num cenário tão adverso, como seria possível conservar alimentos frescos sem energia elé- trica? Como 'botar roçado' e criar galinhas, pescar e caçar, se ao capital mercantil brasileiro, correia de transmissão do capital monopolista internacional, interessava somente à borracha? Como romper com a 'escravização' do seringueiro, sob as amarras do sistema, nos mais diversos aspectos? Como poderia o próprio seringueiro fazer fortuna e voltar para a terra natal, se não fosse se dedicando inteiramente ao corte da seringa?

Em suma, "a exploração do trabalho, a alimentação e as condições ecológicas nos seringais contribuíam para uma situação de saúde que beirava ao (sic) mínimo de subsistência."'16.

Em contraposição à alimentação do seringueiro, o seringalista contava com pessoal suficiente para provê-la, sendo que "em torno do barracão não era raro que houvesse alguma criação de gado e porcos para alimentar o patrão e seus empregados [...]; às vezes um pomar e plantações de produtos alimentícios.". E isso sem contar que, como patrão e empregados geralmente possuíam mulheres, os alimentos eram processados de maneira mais elaborada: "era bastante comum que alguns empregados fossem acompanhados por esposas ou companheiras, que participavam dos trabalhos no dia-a-dia do seringal."

\section{Barraca, seringueiro e borracha: a expropriação do produtor}

Então, era com base na alimentação acima aludida que o extrator do látex deveria prover suas condições físicas para enfrentar o trabalho que lhe era imposto - seja através de regulamentos severos, seja pelas próprias necessidades de aferição de saldo. Este lhe consumia demasiado esforço pessoal, já que iniciava sua labuta diária ainda pela madrugada e só a encerrava ao cair da noite, ocasião em que ainda deveria dispor de forças para o asseio pessoal e para o preparo da refeição noturna. ${ }^{9,11,17,18}$.

Tais regulamentos, no período de maior exigência da produção, constituíam-se em verdadeiras 'amarras', condicionando o extrator a despender sua força de trabalho unicamente à produção de borracha.

A rigidez desses regulamentos mais antigos fica evidente na fala do Seringueiro Cezar Barbosa de Lima, em entrevista concedida a Samuel Benchimol ${ }^{17}$, que veio para o Acre em 1900, quando diz:

Eu só tenho pena é desse pessoal que vem acossado pela seca e que estão chegando agora. Pensam que vão ter liberdade trabalhando no seringal. Eles mal sabem que o seringueiro é um cativo. Trabalha 
de dia e de noite como um cachorro, sem descanso. [...] Eu peguei no meu tempo ainda o tronco. Seringueiro que fugia já sabia. O patrão mandava açoitar sem piedade.

Fato é que no período áureo da produção gomífera existiu uma interdependência socioeconômica entre os principais elos que a fomentaram e a sustentaram, num processo que envolveu desde a arregimentação das forças produtivas até a chegada da produção no mercado internacional. Estabelecia-se um modo de acordo tácito, em que cada um dos elos da cadeia produtiva se via 'obrigado' a fazer com que a produção atingisse sempre seu ápice, pois o que interessava, em última instância, era o lucro.

Se já não era fácil ao extrator nordestino ter que produzir em condição tão diversa do ambiente de onde provinha e com o qual estava acostumado a lidar, essa produção tornava-se ainda mais escorchante e impiedosa pela situação de sua moradia. A estrutura física da barraca consistia, basicamente, de uma pequena construção edificada sobre troncos de madeira de maior resistência ao solo úmido, assoalhada e cercada por paxiúba e coberta por folhas de palmeiras. Possuía no máximo dois cômodos, sendo o quarto de dormir e uma área livre que servia para a guarda de alguns utensílios de trabalho e usada como cozinha. Pelas suas próprias condições materiais, estava essa gente sujeita às intempéries, como chuva, frio, umidade e a presença de animais peçonhentos, eventos que tornavam a vida desprotegida e insalubre ${ }^{9,18}$.

A precariedade das condições de moradia e de higiene do seringueiro manifestava-se, em boa medida, por meio de uma série de aspectos: 1) considerando que a intenção do migrante era apenas ganhar dinheiro, num curto espaço de tempo, e voltar para sua terra natal, não estava preocupado em estabelecer uma condição estrutural mais sólida e permanente; 2) a ganância do capital pela matéria-prima em questão exigia dedicação exclusiva à sua produção; 3) a ausência de uma família que pudesse dividir tarefas, principalmente de uma companheira, sempre mais afeita aos cuidados com o corpo e com a habitação. Tudo se refletia em maior insalubridade das condições da moradia; 4) o corre-corre da lida produtiva não permitia ao seringueiro, na maioria das vezes, mais que um banho diário; 5) a indisponibilidade de sabão fazia com que as roupas não fossem lavadas de forma conveniente; 6) a água de beber era acondicionada, sem nenhum tratamento, em bilhas ou potes; 7) a defecação era feita a céu aberto, usando, no máximo, um tronco caído para, de cócoras, facilitar a evacuação; 8) a limpeza, após a defecação, era quase sempre feita com algum recurso da própria mata, tal como folhas, palhas de milho ou sabugo; 9) as mãos, comumente, não eram lavadas logo após a defecação ${ }^{7,9,18-20}$.

Sem a intenção de desejar estabelecer uma hierarquia entre os tópicos acima mencionados, chama-se a atenção para os de número 6, 7, 8 e 9, por se configurarem como aqueles mais diretamente relacionados com a questão de higiene e de salubridade e, consequentemente, com a saúde do produtor da seringa.

Sobre o tópico 6, água de beber, apesar de esta não passar por nenhum tratamento antes do consumo, não há indícios registrados de que tenha representado fator de risco importante à saúde. Assim, é de se supor, em tese, que a dispersão populacional e seu contingente inexpressivo - dada a dimensão territorial - garantissem a preservação dos cursos de água ou das nascentes utilizadas.

Os tópicos 7, 8 e 9, no entanto, podem ter contribuído significativa e negativamente na questão em pauta, uma vez que se relacionam à principal barreira para a transmissão de patógenos entéricos: a eliminação de fezes de forma segura e a adequada lavagem das mãos com sabão, especialmente depois do contato com material fecal durante a limpeza anal, conforme se pode depreender das análises de Curtis e Cairncross ${ }^{21}$, Bartram e Cairncross ${ }^{22}$ e Ejemot et al. ${ }^{23}$.

Por outro lado, ao serem assentados em suas respectivas colocações, os seringueiros ficavam isolados dos barracões e dos outros tantos seringueiros que, como eles, haviam sido "colocados" ou no mesmo seringal, ou em seringais vizinhos. Isso porque:

1) Se os barracões eram edificados nas margens dos cursos de água, de modo a propiciar o escoamento da produção e a comunicação com as casas aviadoras, as colocações (e nelas as barracas dos seringueiros) eram, por excelência, definidas, assim como também o eram as estradas de seringa, levando-se em conta a própria distribuição natural das árvores produtoras da goma elástica. Como resultado, a comunicação do seringueiro com o patrão seringalista só era possível, na maioria das vezes, via varadouro, por onde, inclusive, o comboio de animais (geralmente burros) transitava para promover o aviamento do seringueiro, transportando instrumentos de trabalho e víveres. Dificilmente coincidia de, na distribuição natural das seringueiras, estas estarem dispostas próximas ao mesmo curso de água 
no qual, em uma de suas margens, havia sido edificado o barracão.

2) As distâncias que separavam uma colocação da outra e, em especial, a barraca do barracão eram demasiadamente grandes, considerando as condições de como eram percorridas;

3) Intimamente relacionado com o item anterior, o trajeto barraca-barracão era feito a pé, já que o seringueiro não dispunha de animal para tal locomoção.

Associada à questão do isolamento, o seringueiro padecia de uma solidão extrema, haja visto que, de modo geral, se por um lado seu vizinho mais próximo morava há dias de distância, por outro não podia contar com a presença de uma companheira e de filhos, já que as regras da arregimentação, como também dos regulamentos, não lhe permitia vir com a família para os seringais, pois, "regiões haviam (sic), numa extensão de dez a doze propriedades, que não se encontrava uma dona de casa [...] Ali não existia mulher [...]."18.

No tocante à ausência da mulher, nos seringais, nos últimos anos, têm sido produzidos trabalhos voltados para a questão de gênero, que tenta desmistificar essa ausência, como o de Wol$\mathrm{ff}^{9}$. A autora, entretanto, admite, em várias passagens de sua obra, que a presença da mulher, pelo menos no limiar da produção, era exceção, e não regra, até porque:

[...] muitos patrões não só não financiavam a vinda de mulheres para seus seringais, como até a desencorajavam, tentando com isso aguçar no seringueiro a vontade de voltar para o Nordeste, e portanto, a necessidade de produzir cada vez mais borracha9.

E, reforçando sua própria afirmativa, diz: "por outro lado, reconhecemos que a maioria das pessoas [que vinham para os seringais do Acre] eram provavelmente esses homens sós [...]"9.

Essa concepção, acerca da ausência da mulher, no Acre, durante a formação dos primeiros seringais já foi sobejamente registrada. Veja-se, por exemplo, que:

Enquanto o outro grupo, o do patrão, dispõe de associações, o do seringueiro é um grupo só. Um homem só. Ele e a floresta. Ele e a árvore de seringa. Ele e a borracha. Ninguém. Mulher, naqueles tempos, não havia, no Acre todo. Era privilégio de pouquíssimos, do patrão, constituído em família, do gerente, do guarda-livros ${ }^{24}$.

A questão do isolamento e da solidão representou uma dimensão significativa de problemas relativos à saúde do corpo e certamente também da mente. No que se refere aos problemas relativos à saúde psicológica, a fala do seringueiro
Francisco Lopes, registrada por Samuel Benchi$\mathrm{mol}^{17}$, que veio para o Acre com um tio em 1906, parece bastante representativa: “A vida lá é muito tristonha. Um silêncio que deixa a gente triste e acabrunhado [...]. Trabalha-se sem gosto e sem vontade. Com um companheiro é bem melhor. [...] Eu não quero mais morar sozinho. Nunca vi vida mais flagelada e tristonha”.

Apesar de tudo isso, há que se argumentar que a Amazônia - e o Acre em particular - simplesmente pelas suas próprias condições físico-naturais, não era insalubre ao migrante e tampouco responsável pelas doenças a que este era acometido. Na verdade, se a ele fossem dadas as condições mínimas necessárias à manutenção do seu bem-estar psicológico e principalmente físico (de higiene e salubridade), provavelmente não teria sofrido de forma tão violenta com doenças como a leishmaniose (a 'ferida braba dos seringueiros'), a tuberculose pulmonar, a hanseníase, o beribéri e a malária, que grassaram - principalmente esta última - durante o processo produtivo ${ }^{25}$.

Além dessas doenças, estava o produtor de borracha suscetível a outros agravos e a acidentes, que eram relativamente comuns, estivesse no interior da barraca ou na estrada de seringa, no corte: picada de cobra, ataque de onça, queda de galho podre ou de ouriço de castanha, desprendidos de árvores de alturas consideráveis. Ocorrendo tais eventos, certamente haveria dificuldades no socorro. Como vencer as distâncias? Como conseguiria caminhar da barraca ao barracão que, no caso do Acre, distava a colocação em média de 3 a 5 dias de viagem a pé? Se chegasse ao barracão, seria 'medicado'? Tinha transporte para conduzi-lo do barracão à cidade mais próxima?

Nesses casos, não era incomum a morte no próprio local do acidente ou, em última instância, no barracão, onde era, no máximo, 'medicado' pelo gerente, com os remédios disponíveis e que haviam sido previamente adquiridos, dada a frequência com que tais acidentes e doenças aconteciam. Afinal, fazia-se necessário manter o seringueiro, ainda que de forma precária, com saúde suficientemente capaz de lhe permitir produzir.

Especificamente, os seringueiros provenientes do Nordeste, na sua maioria analfabetos e supersticiosos, além de trazerem consigo uma maneira própria de tratar certas doenças, com base em rezas e promessas, foram aos poucos incorporando uma cultura curativa indígena e cabocla, que se utilizavam de plantas locais, as quais, muitas vezes, não surtiam os efeitos esperados.

Pelo descrito até aqui, pode-se afirmar que as condições de higiene e salubridade nas coloca- 
ções e, mais pormenorizadamente, no ambiente da moradia do seringueiro, não eram em nada satisfatórias para a proteção da saúde do trabalhador, mas eram coerentes com a política produtiva adotada na fabricação da borracha. Até porque, segundo Dean, para alguns observadores daquele sistema produtivo, "[...] tal forma de organização [...] era a única que os seringueiros aceitariam."26.

\section{Barracão, seringalista e borracha: a apropriação da produção}

E o que dizer da infraestrutura sanitária do barracão, outro elo da representação espacial, política, econômica, e sociocultural da cadeia produtiva da borracha? De modo geral, apresentava características comuns às da barraca, principalmente quando se considera para a análise comparativa apenas a variável das condições 'físico-naturais' que o envolvia.

Entretanto, tais características, mesmo com relação às questões físico-naturais, param por aí, pois, no barracão, havia peculiaridades que, aparentemente insignificantes, fizeram a diferença entre este e a barraca e que por isso mesmo estabeleceram também condições sanitárias diferenciadas entre ambos.

Vale salientar ainda que, se os primeiros barracões possuíam características que em muito os aproximavam das toscas barracas, em seu modelo de simplicidade e desconforto, eles foram, aos poucos, ganhando uma estrutura cada vez mais sofisticada, na proporção em que a produção atingia patamares mais satisfatórios.

O barracão era totalmente fechado e melhor localizado, visto que, por ser edificado às margens de um rio, favorecia o transporte e a comunicação entre este e as casas aviadoras e exportadoras de Belém e Manaus. Em geral, possuía locais apropriados à defecação e ao banho $\mathrm{o}^{7}$, eram iluminados no seu interior por candeeiros a querosene, eram construídos em dois andares, sendo o inferior utilizado como depósito ou armazém de compra, venda e troca de mantimentos e borracha, e o superior para a moradia do seringalista. Posteriormente, o seringalista houve por bem separar, para maior conforto e privacidade, o barracão do armazém ${ }^{18}$.

Essa estrutura dos barracões tinha um sentido: afinal, era a representação do poder do seringalista, o qual, apesar de muitas vezes ser também um migrante nordestino, que veio para a Amazônia-Acre, pelas mesmas razões dos seus compatriotas seringueiros, encontrava-se no topo da cadeia produtiva. Considerando, dentre outros fatores, suas posses e argúcia política, pôde desbravar a selva em que se encontravam as árvores lactíferas e organizar o seringal. Era o empresário, o coronel, o patrão! E, nessa condição, era quem determinava, via regulamento (ou para além deste), o modus operandi da produção. Determinava, por exemplo - e de acordo com a sua visão política, econômica e sociocultural -, a forma de se relacionar com o seu empregado (seringueiro).

\section{Conclusões}

Os sertanejos que vieram para a Amazônia-Acre, no período em discussão, e se fizeram seringueiros ou seringalistas, eram moradores tanto das cidades nordestinas quanto principalmente da zona rural. Quando vinham dessa zona, eram produtores de pequeno, médio e, em alguns casos, grande porte, cujas propriedades enfrentavam as agruras das secas periódicas ${ }^{27}$.

Apesar de a maioria desses migrantes não se enquadrar na condição de cidadãos - uma vez que suas condições socioeconômicas (analfabetos e sem propriedades) não lhes asseguravam essa condição perante a legislação da época ${ }^{28}$-, eram de certa forma homens livres, podendo, a tempo e a hora, ir e vir.

As condições físico-naturais da floresta amazônica em nada tinham relação com a terra de origem. Lá, a quentura e a sequidão; aqui, também quente, mas úmido, e até mesmo por um bom período do ano alagado. Lá, as ruas largas e livres ou as estradas, os caminhos para as glebas; aqui, no máximo os cursos de água e os varadouros, cujos usos requeriam destreza e tenacidade. Havia sempre um 'ar de perigo'. Lá, o transporte ferroviário ou a montaria (cavalo, jumento, burro); aqui, a chata, a gaiola (para as casas aviadoras), o burro (só para o comboieiro), as pernas ou, no máximo, a canoa (para o seringueiro). Lá, pequenas distâncias e fáceis acessos; aqui, o vizinho mais próximo distava cerca de 3 a 5 dias de viagem a pé. Lá, o aglomerado de gente; aqui, a solidão extrema. Lá, a residência, a qual, ainda que tosca, permitia certo conforto; aqui, a barraca, provisória, sem proteção, úmida e sem higiene.

Não se pretende com tais afirmações estigmatizar o seringueiro como uma mera vítima do sistema produtivo e destituído da capacidade de contra ele se insurgir - como de fato alguns o fizeram, utilizando-se de vários métodos, como impregnar a borracha de substâncias estra- 
nhas para aumentar o seu peso ou negociá-las, às escondidas, com os regatões ${ }^{29}$. Tampouco se pretende admitir, de forma generalizada, como aventou Dean ${ }^{26}$, que o "regime de trabalho baseava-se mais nas expectativas de maiores ganhos por parte dos trabalhadores do que pela força, no engodo ou na escravidão por dívidas".

Aliás, ao seringueiro, último elo da cadeia produtiva, foram disponibilizadas apenas as condições materiais mínimas necessárias ao trabalho da extração do látex, da defumação e da feitura das pelas de borracha, principalmente durante o rush da produção, pois ao capital não interessava as suas condições físicas e psicológicas. Não interessava sua cultura, seus modos de vida, sua família, sua terra natal... Não interessava nada mais além da produção de borracha. E a borracha era produzida em meio às condições precárias de higiene e insalubridade dos seringais. Condições essas muito mais perversas aos seringueiros do que qualquer outro elo da cadeia produtiva, que culminou com um número alarmante de mortes.

Quanto ao número de mortos, nenhuma estatística precisa é identificada na literatura, nem mesmo para o período relativo ao segundo surto. Até porque, "quantos partiram, quantos chegaram, quantos morreram, a crônica [também] não registrou." ${ }^{17}$. Entretanto, considerando-se que o número de migrantes que veio para a Amazônia entre os anos de 1877 a 1900 somou em torno de $158.000^{17}$, bem como nesse período ocorreu algo idêntico ao verificado na década de 1900, onde " $[. .$.$] a mortalidade elevada era a principal$ causa de escassez de mão de obra, o que obrigava o recrutamento contínuo de nordestinos, talvez 14.000 por ano [...]." ${ }^{26}$, presume-se uma soma expressiva de mortes no período estudado.

Conclui-se, então, que as condições de infraestrutura e sanitária nos seringais do Acre, durante o primeiro surto da produção gomífera, devem ser compreendidas numa perspectiva histórica das condições físico-naturais, socioeconômicas, políticas e culturais. Os efeitos do ambien- te sobre o processo saúde-doença, nos seringais, nesse período estudado, revelam uma situação de eloquente iniquidade e desumanidade, se avaliados sob a lente dos padrões contemporâneos. Este relato ressalta, no entanto, a indissociável mediação da relação ambiente-saúde, realizada pela dinâmica do processo produtivo, que colocava a obsessão pela maximização de excedentes econômicos, acima de qualquer cuidado com a saúde dos trabalhadores na seringa.

\section{Colaboradores}

DJ Almeida Neto trabalhou na pesquisa, na metodologia e na redação; e L Heller trabalhou na concepção do texto final.

\section{Agradecimentos}

À CAPES, pelo apoio ao programa de Doutorado Interinstitucional em Saneamento, Meio Ambiente e Recursos Hídricos, celebrado entre a Universidade Federal de Minas Gerais e a Universidade Federal do Acre.

À nutricionista Katiuscia Shirota Imada, professora do Curso de Nutrição da UFAC, pela elaboração e análise da Tabela 1 - Análise nutricional dos alimentos que faziam parte da refeição diária dos seringueiros, na condição de produtores exclusivo da borracha. 


\section{Referências}

1. Porto MFS, Almeida GES. Significados e limites das estratégias de integração disciplinar: uma reflexão sobre as contribuições da saúde do trabalhador. Cien Saude Colet 2002; 7(2):335-347.

2. Tambellini AT, Câmara VM. A temática saúde e ambiente no processo de desenvolvimento do campo da saúde coletiva: aspectos históricos, conceituais e metodológicos. Cien Saude Colet 1998; 3(2):47-59.

3. Weihs M, Mertens F. Os desafios da geração do conhecimento em saúde ambiental: uma perspectiva ecossistêmica. Cien Saude Colet 2013; 18(5):1501-1510.

4. Heller L, Castro JE, organizadores. Política pública e gestão de serviços de saneamento. Ed. Ampl. Belo Horizonte, Rio de Janeiro: Editora UFMG, FIOCRUZ; 2013.

5. Brasil. Decreto-Lei no 5.452, de $1^{\circ}$ de maio de 1943. Aprova a Consolidação das Leis do Trabalho. Diário Oficial da União 2001; 14 set.

6. Paravicini J. In: Paravicini J. Acre: relatórios de governo (1899 a 1905) - os anos do conflito. v. 1. Rio Branco: Gráfica do Tribunal de Justiça do Estado do Acre; [2002?]. p. 10-83.

7. Esteves AR. A ocupação da Amazônia. São Paulo: Brasiliense; 1993. (Tudo é história, n.143).

8. Rocha AC. Trabalho e dominação nos seringais do Acre [dissertação]. São Paulo: Pontifícia Universidade Católica de São Paulo; 1998.

9. Wolff CS. Mulheres da floresta: uma história do Alto Juruá, Acre (1890-1945). São Paulo: Hucitec; 1999.

10. Castelo Branco JMB. O povoamento da Acreânia. $R$. IHGB 1961; 250:118-256.

11. Cunha E. À margem da História: batalha do ouro negro. Rio Branco: Tribunal de Justiça; 2003.

12. Phillipi ST. Tabela de Composição de Alimentos: suporte para decisão nutricional. $2^{\text {a }}$ ed. São Paulo: Coronário; 2002.

13. Mattos RCM. In: Acre: relatórios de governo (1899 a 1905) - os anos do conflito. v. 1. Rio Branco: Gráfica do Tribunal de Justiça do Estado do Acre; [2002?]. p. 87135.

14. Peixoto A. O problema sanitário da Amazônia. In: Cruz O, Chagas Filho C, Peixoto A, organizadores. Sobre o saneamento da Amazônia. Manaus: P. Daou; 1972. p. 179-205.

15. Castro J. Geografia da fome. (o dilema brasileiro: pão ou aço). Rio de Janeiro: Edições Antares; 1984. (Clássicos das Ciências Sociais no Brasil).

16. Schweickaedt JC. Ciência, nação e região: as doenças tropicais e o saneamento no Estado do Amazonas (18901930) [tese]. Rio de Janeiro: Casa de Oswaldo Cruz; 2009.
17. Benchimol S. Amazônia: um pouco - antes e além - depois. Manaus: Umberto Calderaro; 1977. (Amazoniana, n. 1).

18. Reis ACF. O seringal e o seringueiro. Rio de Janeiro: Serviço de Informação Agrícola; 1953. (Documentário da vida rural, 5).

19. Cabral AL. Dez anos no amazonas (1897-1907). Brasília: Gráfica do senado; 1984.

20. Ranzi CMD. Raízes do Acre. Rio Branco: EDUFAC; 2008.

21. Curtis V, Cairncross S. Effect of washing hands with soap on diarrhea risk in the community: a systematic review. The Lancet 2003; 3(5):275-281.

22. Bartram J, Cairncross S (2010) Hygiene, sanitation, and water: forgotten foundations of health. PLoS Med 7. [serial on the Internet]. 2010 nov 9 [acessado 2014 abr 7]. Disponível em: http://www.plosmedicine.org/article/info\%3Adoi\%2F10.1371\%2Fjournal. pmed. 1000367

23. Ejemot RI, Ehiri JE, Meremikwu MM, Critchley JA. Hand washing for preventing diarrhoea (Review). Cochrane Database Syst Rev. [serial on the Internet].2009 [acessado 2014 abr 7]. Disponível em: http://ije.oxfordjournals.org/content/39/suppl_1/i193.full.pdf

24. Tocantins L. Formação Histórica do Acre. Rio de Janeiro: Civilização brasileira; 1979.

25. Chagas Filho C. Exploração das questões médico-sanitárias em diversos rios da bacia Amazônica - Relatório de viagem. In: Cruz O, Chagas Filho C, Peixoto A, organizadores. Sobre o saneamento da Amazônia. Manaus: P Daou; 1972. p. 53-118.

26. Dean W. A luta pela borracha no Brasil: um estudo de história ecológica. Tradução de Eduardo Brandão. São Paulo: Ed. Nobel; 1989.

27. Santos R. História econômica da Amazônia (18001920). São Paulo: T. A. Queiroz; 1980.

28. Ferreira MR. A evolução do sistema eleitoral brasileiro. Ebooksbrasil. 2005 [acessado em 2014 mar 11]. Disponível em: http://www.ebooksbrasil.org/eLibris/eleitoral.html

29. Almeida Neto DJ. 'Aos trancos e barrancos': identidade, cultura e resistência seringueira na periferia de Rio Branco-Acre (1970-1980). Rio Branco: EDUFAC; 2004.

Artigo apresentado em 01/07/2014

Aprovado em 11/07/2014

Versão final apresentada em 12/07/2014 